\title{
OS PERIGOS DA ESCOLA SEM PARTIDO
}

\author{
Karla Saraiva. \\ Juliana Ribeiro de Vargas $^{(*)}$
}

O objetivo deste artigo é problematizar os perigos que a disseminação das ideias do Movimento Escola Sem Partido (ESP) (im)põe para a Educação, uma vez que elas vêm se capilarizando junto a crescentes segmentos da sociedade, e estão em consonância com aquelas de outros movimentos igualmente conservadores. Tomamos como hipótese que seus pressupostos são fortemente embasados por uma racionalidade fundamentalista cristã, que vem sendo assumida por indivíduos que não estão ligados diretamente a esses grupos religiosos, sinalizando um fenômeno cultural que se expande e que estabelece um regime de verdade cada vez mais consolidado. Também subsidia este Movimento uma orientação política de profundo repúdio à esquerda. Cabe também ressaltar que o ESP está alinhado com um pensamento conservador que vem se consolidando progressivamente não apenas no Brasil, mas também no cenário internacional ${ }^{1}$.

Na próxima seção, tratamos da emergência da ESP e dos perigos que este Movimento coloca para a docência. Na seção seguinte, problematizamos a relação dos alunos com o ESP. Finalizamos o artigo com algumas considerações finais.

\section{A INVENÇÃO DA ESCOLA SEM PARTIDO E A PRODUÇÃO DO PROFESSOR PARRESIASTA}

O Movimento Escola sem Partido (ESP) começa a tomar forma no ano de 2004, de acordo com um de seus líderes, o católico praticante e procurador do Estado de São Paulo, Miguel Nagib. Segundo ele, tudo começou quando um professor de sua filha teria comparado Che Guevara a São Francisco de Assis. Revoltado, tentou sensibilizar outros pais com a distribuição de 300 cópias de uma carta aberta. Porém, isto gerou repúdio dos alunos, dos professores e, ainda, indiferença dos pais. Sem nenhum respaldo na escola de sua filha, resolveu buscar apoio fora dali, criando uma associação que teria por finalidade "lutar contra o abuso do qual as crianças estão sendo vítimas" (EL PAÍs, 2016a, online).

\footnotetext{
${ }^{(*)}$ Karla Saraiva. Universidade Luterana do Brasil (ULBRA) E-mail: karlasaraiva@ @ia-rs.net. Juliana Ribeiro de Vargas. Universidade Luterana do Brasil (ULBRA). E-mail: julivargas10@hotmail.com.

${ }^{1}$ Podemos citar como exemplos o aumento da representatividade de partidos de extrema direita em países como França e Alemanha nos últimos pleitos (2016/2017) e, ainda, a vitória de Donald Trump na última eleição presidencial norteamericana.
} 
A proveniência do ESP, como já comentamos, estaria ligada a grupos de extrema direita e a grupos religiosos fundamentalistas de orientação cristã, insatisfeitos com as ações do Governo de centro-esquerda de Luiz Inácio Lula da Silva (Lula), que assumiu a presidência em 2003. Cabe notar que muitas das políticas educacionais adotadas pelo Governo Lula promoviam inclusão social, combate ao racismo, à violência de gênero e à homo e transfobia, entre outros temas. Tais políticas eram coordenadas inicialmente pela Secretaria de Educação Continuada, Alfabetização e Diversidade (Secad), instituída em julho de 2004 (BRASIL, 2004). Observe-se que a Secad, que tinha justamente como um dos eixos a diversidade, no âmbito da qual seriam tratados os temas supracitados, foi instituída no mesmo ano em que foi fundado o ESP.

A Secad tornou-se, em 2011 (BRASIL, 2011), Secretaria de Educação Continuada, Alfabetização, Diversidade e Inclusão (Secadi), visando à “[...] valorização das diferenças e da diversidade, à promoção da educação inclusiva, dos direitos humanos e da sustentabilidade socioambiental, visando à efetivação de políticas públicas transversais e intersetoriais” (BRASIL, 2017a, online). Vale destacar que a Secadi promoveu, até 2015, ações diversas na Educação Básica e no Ensino Superior visando à redução das desigualdades, a exemplo do Prêmio Construindo a Igualdade de Gênero, da produção de diversas publicações voltadas à formação de professores, bem como da produção das Diretrizes Curriculares Nacionais para a Educação Básica: diversidade e inclusão. Entendemos que tais mudanças nas ações e das políticas educacionais no âmbito do MEC, que ressoam discussões que vinham e vêm ganhando espaço no Brasil, integram-se a um conjunto de condições de possibilidade para a emergência do ESP. Neste sentido, percebemos o Movimento como uma resistência a possíveis transformações sociais que venham a empoderar grupos historicamente assujeitados e a promover a inclusão dos excluídos, no intuito de conservar as posições privilegiadas e hegemônicas de alguns segmentos.

O Movimento fundado por Nagib assume o nome Escola sem partido numa visível tentativa de sensibilizar a sociedade ao reduzir a micropolítica que atravessa a sala de aula à macropolítica partidária. A forma simples do slogan propicia uma adesão imediata por parte daqueles que não conseguem ou que não querem fazer uma análise mais profunda das propostas deste movimento. Afinal, a imensa maioria dos indivíduos, incluindo as autoras, concordará que as escolas não podem ser orientadas por doutrinas partidárias. Contudo, a simplicidade do slogan deve ser problematizada, uma vez que já é amplamente reconhecido, desde meados do século 20, que o currículo é atravessado por relações de poder e se constitui em um campo de lutas (LOPES; MACEDO, 2011). 
Vale destacar que a própria legislação reconhece este caráter político quando a Lei de Diretrizes e Bases da Educação (LDB) (BRASIL, 1996) e as Diretrizes Curriculares para a Educação Básica (BRASIL, 2010) colocam que as escolas deverão orientar seu trabalho por meio de um projeto político-pedagógico. Deste modo, é possível afirmar que a escola deve ser sem partido, mas nunca deixará de ser um campo político. As escolhas que constituem um currículo são sempre escolhas políticas e querer designar um modelo educacional como sendo neutro é assumir uma postura arrogante que visa fechar o debate por meio da universalização do que é contingente e parcial.

O ESP mantém um site que divulga suas ideias, denominado Movimento Escola sem Partido (ESP, 2017a) e outro que divulga projetos de lei em tramitação no âmbito federal, estadual e municipal, denominado Programa Escola sem Partido (ESP, 2017b). A “Apresentação” do primeiro site deixa claro que a preocupação do Movimento está relacionada com uma suposta doutrinação dos alunos por parte dos professores: "Vítimas do assédio de grupos e correntes políticas e ideológicas com pretensões claramente hegemônicas, [as] escolas se transformaram em meras caixas de ressonância das doutrinas e das agendas desses grupos e dessas correntes” (ESP, 2017a, online). Mais adiante, o site detalha um pouco melhor o que seria esse assédio e incita os alunos e pais a denunciarem professores:

Se você sente que seus professores ou os professores dos seus filhos estão comprometidos com uma visão unilateral, preconceituosa ou tendenciosa das questões políticas e sociais; se percebe que outros enfoques são por eles desqualificados ou ridicularizados e que suas atitudes, em sala de aula, propiciam a formação uma atmosfera de intimidação incompatível com a busca do conhecimento; se observa que estão engajados na execução de um projeto de engenharia social, que supõe a implementação de uma nova escala de valores, envie-nos uma mensagem relatando sua experiência (ESP, 2017a, online).

Portanto, o ESP incita uma política de coação e intimidação de docentes. Observe-se que a generalidade dos argumentos torna a noção de doutrinação e assédio moral tão ampla que poderia inviabilizar a própria escolarização. Afinal, o que seria uma nova escala de valores que embasa um suposto projeto de engenharia social? Possivelmente, nem mesmo os apoiadores do movimento compartilhem dos mesmos valores, o que dirá o conjunto da sociedade. Para implantar suas ideias, o Movimento espera valer-se de denúncias por parte de pais e alunos. Um menu localizado à esquerda do site tem a forma de um manual para o controle da ação docente. Ele é constituído pelos seguintes links (ESP, 2017a):

- Por uma lei contra o abuso da liberdade de ensinar

- Modelo de notificação extrajudicial

- Flagrando o Doutrinador 
- Planeje sua Denúncia

- Conselho aos Pais: "Processem por dano moral as escolas e os professores que transmitirem conteúdos imorais aos seus filhos"

Indo na mesma direção, o site do Programa Escola sem Partido (ESP, 2017b) destaca em sua primeira página um excerto do Projeto de Lei (PL) que tramita no Congresso Nacional para implantar este Programa em todas as escolas do país fixando, em todas as salas de aula, um cartaz com o que entende ser os deveres do professor.

1. O Professor não se aproveitará da audiência cativa dos alunos para promover os seus próprios interesses, opiniões, concepções ou preferências ideológicas, religiosas, morais, políticas e partidárias.

2. O Professor não favorecerá nem prejudicará ou constrangerá os alunos em razão de suas convicções políticas, ideológicas, morais ou religiosas, ou da falta delas.

3. O Professor não fará propaganda político-partidária em sala de aula nem incitará seus alunos a participar de manifestações, atos públicos e passeatas.

4. Ao tratar de questões políticas, socioculturais e econômicas, o professor apresentará aos alunos, de forma justa - isto é, com a mesma profundidade e seriedade -, as principais versões, teorias, opiniões e perspectivas concorrentes a respeito da matéria.

5. O Professor respeitará o direito dos pais dos alunos a que seus filhos recebam a educação religiosa e moral que esteja de acordo com suas próprias convicções.

6. O Professor não permitirá que os direitos assegurados nos itens anteriores sejam violados pela ação de estudantes ou terceiros, dentro da sala de aula. (ESP, 2017b, online)

O destaque dado a esta parte do PL na composição da capa do site sinaliza que o ESP tem como foco principal a criminalização docente, individualizando responsabilidades e buscando constranger o exercício profissional dos educadores. Note-se, ainda, que consta no art. $8^{\circ}$ do PL que “os alunos matriculados no ensino fundamental e no ensino médio serão informados e educados sobre o conteúdo desta Lei”. Portanto, também aqui é possível perceber que o ESP espera contar com a colaboração dos próprios alunos para cercear a ação dos professores, instaurando um clima de denuncismo nas escolas. Neste mesmo sentido, o site do Movimento apresenta uma seção intitulada "Flagrando o doutrinador", em que lista uma série de procedimentos que caracterizariam doutrinação para que os alunos possam flagrar estes "mestres da militância" (ESP, 2017a). Voltando ao PL, ele também aponta que o disposto na lei deve ser aplicado a outras instâncias, como projetos pedagógicos, materiais didáticos, provas de concurso, porém listadas genericamente e com pouca ênfase (ESP, 2017b). 
A partir da análise dos conteúdos dos sites do ESP, é possível dizer que existem dois grandes focos de preocupação: a discussão de questões que possam minimamente parecer pautas políticas de esquerda (aí incluindo a discussão de conceitos sociológicos e filosóficos, bem como orientações pedagógicas e temas da atualidade, como políticas públicas de inclusão) e temas relacionados com gênero e sexualidade. Uma das seções do site é intitulada "Doutrina da doutrinação" (ESP, 2017a), com foco no que consideram doutrinação política. Todos os casos relatados na página estão ligados a posicionamentos políticos de esquerda, sinalizando que orientações à direita não seriam consideradas doutrinação.

Esta implícita aceitação de uma orientação de direita pode estar ligada não apenas a valores do Movimento ESP, mas a fatores culturais mais abrangentes. Como alguns autores da Sociologia já mostraram, entre eles Varela e Alvarez-Uría (1996), a escola, desde sua emergência naturalizou a transmissão de um conjunto de valores da cultura burguesa europeia, que acabaram sendo tomados como universais. A disseminação destes valores reduz a força política e conforma os alunos à estrutura social vigente. Portanto, a transmissão de valores tradicionais deixou de ser percebida como doutrinação, sendo entendida como uma transmissão de verdades, em contraponto à transmissão de valores de viés mais progressista, que passaram a ser tomados como doutrinação.

Este mesmo raciocínio estende-se aos temas gênero e sexualidade, considerados por muitos também como pautas de esquerda. O site em questão apresenta outra seção intitulada "Educação Moral", em que denuncia situações em que as escolas estariam atentando contra os valores cristãos e familiares. Entre outros casos, destacamos a notícia sobre uma festa junina, ocorrida em uma escola em Brasília. Durante a brincadeira do casamento caipira, o noivo (um aluno do ensino médio) abstém-se do matrimônio, fugindo com outro homem. De acordo com a manchete do site, "No DF, professores usam festa junina para atacar moralidade cristã, e transmitir aos filhos dos outros seus próprios valores" (ESP, 2017a).

Conforme se pode observar, o controle e a criminalização da ação docente se conjugam com uma exortação para que os pais e alunos ajam de forma policialesca, denunciando os docentes que agirem de modo que considerem inadequado. E por inadequado entenda-se que apresentem a seus filhos conteúdos com os quais estejam em desacordo. Boa parte da argumentação que sustenta o ESP está pautada no parágrafo 4 do artigo 12 da Convenção Americana de Direitos Humanos: “Os pais, e quando for o caso os tutores, têm direito a que seus filhos ou pupilos recebam a educação religiosa e moral que esteja acorde com suas próprias convicções” (CIDH, 1969, online). Visando garantir este suposto direito dos pais, o site da ESP apresenta um modelo de notificação extrajudicial a ser utilizado para impedir que os professores tratem de temas indesejados. Segundo o 
grupo isto traria benefícios que se estenderiam a toda escola: "Pense que, se a notificação produzir o efeito esperado, sua iniciativa reverterá em benefício de todos os alunos do professor notificado, e não apenas do seu filho. Trata-se, portanto, de um serviço de utilidade pública" (ESP, 2017a, online). Tal afirmativa evidencia, mais uma vez, a presunção de universalidade de suas crenças e valores por parte do movimento.

Em um vídeo postado no site YouTube, Guilherme Schelb, que se apresenta como Procurador Regional da República ${ }^{2}$, incita os pais a acessarem este modelo e realizarem a notificação, usando como argumento o relato de eventos e temas inadequados que seriam comuns nas escolas, mas que não correspondem às práticas que usualmente se observam no cotidiano, numa clara tentativa de desqualificar as discussões sobre gênero e sexualidade no âmbito dessas instituições. E embasa a legitimidade do ato invocando o já referido Artigo da Convenção Americana de Direitos Humanos. A Procuradoria Federal dos Direitos dos Cidadãos abriu um procedimento administrativo para análise deste vídeo e emitiu uma nota técnica em 17 de março de 2017 (BRASIL, 2017b), desenvolvida em um documento que apresenta uma longa e bem embasada discussão jurídica sobre o tema.

Em síntese, a Procuradoria declara que o direito dos pais de proverem aos filhos uma educação alinhada a seus princípios morais e religiosos está restrito ao âmbito das ações educativas que se dão fora da escola, sejam na família ou em comunidades quaisquer. A escola, sendo uma instituição que atende a um amplo público, deve ser pautada por princípios gerais. Segundo os procuradores, existe jurisprudência internacional que reconhece o direito das crianças a uma educação que dê acesso a múltiplas visões de mundo, a um pensamento plural e ao desenvolvimento de respeito aos direitos humanos. Além disso, tendo em vista os múltiplos grupos que circulam na escola, um pai ou um grupo de pais não pode impor sua vontade sobre todos. Por fim, a nota destaca que a censura a temas ligados a gênero e sexualidade contribuiria para o estabelecimento de um clima de hostilidade contra indivíduos identificados como LGBTs, ameaçando seu acesso e permanência na escola. Sendo assim, é dever do Estado orientar para que ocorra a discussão desses temas no âmbito das instituições escolares, sendo a notificação sugerida pelo ESP considerada inconstitucional.

Conforme afirmamos, o Movimento se mostra preocupado com o que seria uma doutrinação ideológica de esquerda e foca na coerção e na censura para atingir seus objetivos. Tratar de qualquer tema que possa ter alguma relação com o que considerem uma orientação política de

\footnotetext{
${ }^{2}$ Assista o vídeo em:< https://www.youtube.com/watch?v=fufoZITaRDI $>$.
} 
esquerda, incluindo-se discussões sobre gênero e sexualidade e temas da cultura afro-brasileira, passa a ser considerado doutrinação. A partir dos conteúdos do site, parece-nos que o Movimento não apenas tem uma orientação política de direita, como de uma direita orientada por uma política de mercado e não uma direita nacionalista e intervencionista, pois se coloca contra intervenções estatais em geral. Ao mesmo tempo em que são dogmáticos em termos morais, filiam-se à liberdade de mercado. Neste sentido, parece-nos que o que fundamenta o ESP e grupos semelhantes seja uma mistura de um conservadorismo moral com um forte apoio a uma política de mercado. Dito de outro modo, uma associação entre uma cultura fundamentalista cristã e neoliberalismo.

Cabe notar que as teorizações acerca do neoliberalismo são bastante diversas, porém um princípio amplamente aceito é de que a liberdade do mercado é produzida pela liberdade individual, pela competição entre indivíduos diferentes entre si (FOUCAULT, 2008). Portanto, esta articulação que aparece como fundamento não apenas do ESP, mas de outros movimentos nacionais, como o Movimento Brasil Livre (MBL), e internacionais, como o Tea Party, parece ser a condição de emergência de uma direita disciplinarmente normativa em termos sociais, considerando como válidos apenas seus valores tradicionais, e desregulamentadora em termos econômicos, acreditando em um grande jogo de mercado em que cada um joga com as armas que dispõe. Ou seja, esta nova direita apresenta uma dupla dificuldade em lidar com a alteridade: falta-lhe capacidade para entender como legítimas formas de vida diferentes das suas e empatia para preocupar-se com mecanismos de promoção de justiça social.

Os perigos que cercam os professores com a disseminação das ideias do ESP ficam evidenciados quando analisamos casos concretos de denúncias realizadas de modo arbitrário que resultaram em punições. Um veículo de comunicação fez, em 2016, uma reportagem em que apresenta alguns casos bastante graves, no nosso entendimento. Um dos relatos refere-se a uma professora que foi filmada secretamente durante 40 minutos, enquanto conversava com os alunos sobre as razões que estavam levando os professores da rede paranaense a entrarem em greve (DIP, 2016). Outra, docente de Sociologia, foi denunciada, pois os alunos fizeram uma paródia em ritmo de funk para trabalhar com os conceitos de Marx (DIP, 2016). Já em Uruguaiana (RS), no presente ano, um vereador do partido Democratas (DEM) utilizou os cartazes construídos pelos alunos em uma aula sobre cidadania como exemplo de doutrinação em uma audiência pública, fazendo com que a professora responsável pela atividade, ligada à rede municipal, fosse removida para outra escola. Esta mesma reportagem traz, ainda, um incidente ocorrido com uma professora do Departamento de História da UFRGS, que sofreu ameaças nas redes sociais por ministrar uma 
palestra sobre a cultura do estupro (DCM, 2017). Em diversos casos, professores foram notificados, demitidos e transferidos de escolas por discutirem gênero e sexualidade.

Frente a isto, parece-nos que o ESP vem tornando a docência um ato que exige uma coragem da verdade, sendo a verdade enunciada em nome próprio e não um universal. Aqui, nos colocamos na esteira de Foucault (2009, p.311), para quem: "não existe instauração de verdade sem uma posição essencial de alteridade; a verdade, nunca é a mesma; não pode haver verdade que na forma de um outro mundo e de uma vida outra". A verdade, em Foucault, é uma verdade da transgressão, é aquilo que faz diferença no mundo e altera os modos de vida.

Este filósofo dedicou os dois últimos cursos que ministrou no Collège de France ao estudo da enunciação da verdade entre os gregos da Antiguidade. Para ele, haveria quatro modalidades de enunciação da verdade naquela cultura: o profeta, que fala em nome de uma divindade; o sábio, que fala em nome próprio, mas enuncia verdades que dizem o que é o mundo e não como deveria ser; o professor, que ensina um conhecimento que aprendeu anteriormente, uma tehknê; e o parresiasta, aquele que tem a parresía, o franco falar, que enuncia verdades em nome próprio, seja no âmbito político ou como conselheiro ético, visando intervir nas condutas e decisões dos outros. O parresiasta se afasta de todos os outros três enunciadores da verdade por enunciar uma verdade que muitas vezes incomoda seus interlocutores, colocando-o em risco. Seja o parresiasta político, que toma a palavra na assembleia, seja o parresiasta ético, que aconselha um governante, em qualquer caso ele se arrisca ao falar em nome próprio e pode sofrer sanções por causa das verdades que enuncia. Neste sentido, aquele que ensina e o parresiasta constituíam duas figuras distintas e a escola não seria o lugar da parresía.

O ESP funde estas duas figuras ao colocar em perigo o professor que enuncia verdades que aprendeu, mas que também fala em nome próprio. A criminalização da ação docente coloca os professores na situação de parresiastas que não enunciam suas verdades nem na assembleia política, nem como conselhos éticos a um governante, mas na sala de aula para seus alunos. A enunciação de uma verdade incômoda para os simpatizantes do ESP pode ser motivo tanto de punições institucionais, como de ameaças privadas, como já sofreram muitos docentes, dos quais trouxemos apenas uns poucos exemplos. Às dificuldades de longa data enfrentadas pelos professores, como baixa remuneração e más condições de trabalho, soma-se ainda esta: o perigo de falar em nome próprio, a necessidade de uma censura permanente, a sujeição aos ditames conservadores de um grupo que, apesar de parecer numeroso e barulhento, está longe de representar a sociedade de modo 
global $^{3}$. Porém, se o ESP involuntariamente produz professores parresiatas, voluntariamente pretende tornar os alunos reféns d'A Vila.

\title{
MANTENDO OS ALUNOS DENTRO DA VILA
}

Como já destacamos, o ESP diz se apoiar na Convenção Americana de Direitos Humanos, mais especificamente no artigo 12, que trata do direito dos pais educarem seus filhos segundo seus valores morais e religiosos. Porém, parece esquecer o Artigo 13, em que consta que

\begin{abstract}
toda pessoa tem direito à liberdade de pensamento e de expressão. Esse direito compreende a liberdade de buscar, receber e difundir informações e ideias de toda natureza, sem consideração de fronteiras, verbalmente ou por escrito, ou em forma impressa ou artística, ou por qualquer outro processo de sua escolha (CIDH, 1969, online).
\end{abstract}

O ESP, ao permitir que os pais cerceiem a possibilidade de que seus filhos (bem como seus colegas) entrem em contato com ideias que divirjam das suas, faz exatamente o oposto do que consta no artigo 13: amordaça a escola e os professores e censura conhecimentos. Aqui, invocamos o filme A vila, uma produção de 2004, dirigida por Shyamalan, que inicia mostrando cenas de uma comunidade que parece viver no século XIX. Ela é governada pelo Conselho dos Anciãos e seus habitantes nunca podem se afastar dos limites demarcados, sob pena de serem atacado por "aqueles dos quais não falamos" - monstros desconhecidos e ferozes, que são atraídos pela cor vermelha.

Aos poucos, vamos percebendo que existe algo errado naquela comunidade: segredos guardados pelos anciãos, conversas estranhas. Até que em determinado momento, compreendemos que a vila é uma comunidade que vive no século $\mathrm{XX}$, porém isolada para levar a existência nos moldes do século XIX. Esta decisão foi tomada há muito tempo por aqueles que formam o Conselho dos Anciãos. Cada um deles traz um drama pessoal que fez com que desejasse deixar o mundo atual para trás para se refugiar em um passado mítico, em que a vida seria mais pacífica e mais feliz. Decidiram trocar a liberdade por uma suposta segurança - tanto a sua, quanto a de seus descendentes. Portanto, no filme os pais decidem e controlam rigidamente o que os filhos irão experimentar e que saberes irão acessar, afastando-os de qualquer espécie de alteridade, no intuito

\footnotetext{
${ }^{3}$ A censura vem se disseminando como estratégia junto a grupos com orientação política análoga à do ESP. Em setembro de 2017, o Movimento Brasil Livre, associado com outros como o Terça Livre, conseguiu, por meio de uma forte pressão, que o Santander Cultural fechasse uma exposição intitulada Queermuseu. Na mesma semana, o deputado e pastor evangélico Marcos Feliciano tentou fechar uma exposição em Brasília e o MBL tentou censurar a apresentação de uma peça teatral em que Jesus era representado por uma mulher trans (EL PAÍS, 2017, online). Em abril de 2017, o vereador Fernando Holiday, também ligado ao MBL, fez blitz nas escolas para flagrar doutrinação (ESTADÃO, 2017, online).
} 
de preservar o modo de vida que acreditam ser o melhor. Estes filhos já são adultos e vivem sem qualquer conhecimento do mundo além dos limites da vila.

Parece-nos que este filme possa ser tomado como uma alegoria do que pretende a ESP: os pais outorgando para si o direito de decidir sobre os modos de vida de seus filhos. "Aqueles dos quais não falamos" torna-se "aquilo do qual não falamos", traduzindo-se pelos temas colocados como tabus pelo Movimento. A associação com os monstros que assombram o imaginário dos habitantes da vila fica patente quando encontramos em uma seção do site do ESP, intitulada Síndrome de Estocolmo, uma matéria cujo título é "Monstro totalitário arreganha os dentes", referindo-se a uma professora do Departamento de História da UFF que estaria, supostamente, utilizando sua posição para a doutrinação de alunos (ESP, 2017a).

Destacamos, ainda, outra simbologia que parece importante: os monstros eram atraídos no filme pela cor vermelha. Sendo assim, os habitantes da vila deveriam evitar esta cor. Não deveriam ter roupas e objetos, nem mesmo consumir alimentos, vermelhos. Cor do sangue, cor da vida que pulsa no corpo. Portanto, era a própria vitalidade que a vila drenava de seus habitantes. Uma vida acinzentada, sem calor. Uma vida morta. Uma vida que perdia sua potência ao neutralizar o acontecimento que é sempre da ordem do inesperado, que é o que irrompe no tempo, intempestivo, imprevisível, ameaçador e arriscado. Uma vida sem devir. Na busca de segurança, matam-se as possibilidades de criação do mundo.

O ESP também pretende vetar o vermelho no ambiente escolar, entendendo-se a metáfora de forma ampla ${ }^{4}$. Também pretende embotar a vida que pulsa na escola. Vetar o vermelho é emudecer vozes que dão cor à escola. Uma escola amordaçada é uma escola assujeitada, amortecida. Em que se procura esconjurar o acontecimento que transforma as subjetividades pela força de um trabalho educacional plural. Pois é importante afirmar que um currículo e uma ação docente que se propõem a tensionar o mundo em que os alunos estão implicados traz a possibilidade de colocar em movimento processos de subjetivação, porém com resultados não podem ser previstos. Ao dizer-se neutra e apolítica, ela naturaliza e reforça as formas conhecidas do viver. Ao pretender ensinar apenas conteúdos neutros e úteis, rende-se a uma lógica de mercado. Portanto, uma escola que se diz neutra tem, sim, uma orientação política. Uma orientação que visa formar subjetividades capitalísticas conservadoras e voltadas para a defesa de seus próprios interesses individuais. Uma escola que não se abre para a alteridade e que não discute o social, fecha os indivíduos em si

\footnotetext{
${ }^{4}$ Se os monstros d'A vila eram atraídos pelo vermelho, também é o vermelho, cor associada à esquerda, que atiça a ira da ESP.
} 
mesmos. Simon e Masschelein (2013) afirmam que a escola deve apresentar o mundo às novas gerações, para que elas possam tomá-lo para si e transformá-lo. O ESP, ao impedir que os alunos acessem um mundo que é muito mais amplo do que aquele circunscrito por seus pais, sonega-lhes a possibilidade de tomar o mundo e de transformá-lo em algo diferente.

Porém, no filme, se os anciãos desejavam reter os habitantes no limite da vila, lançando mão de todo tipo de estratagema para atingir seu objetivo, havia um jovem corajoso, cujo nome era Lucius, que desejava enfrentar os perigos que cercavam a vila e aventurar-se para conhecer o mundo além dos seus limites. Ultrapassar os limites: transgredir. Lucius pretendia ser um transgressor, pretendia traçar linhas de fuga daquela vila triste, rompendo as segmentaridades duras que o prendiam àquele território. E pediu autorização ao Conselho de Anciãos, que lhe foi negada. Lucius, luz. A luz que se vê ao sair da caverna platônica, indo em busca de outros mundos com outras racionalidades. Lucius não se satisfazia com o que aquele mundo lhe oferecia e suspeitava que para além dos limites havia um mundo muito maior e muito mais instigante. Lucius sabia da necessidade de transgredir, de correr riscos, para pode acessar este mundo maior. Ele estava pronto para enfrentar os monstros da floresta para realizar o seu propósito.

Assim como Lucius não queria permanecer nos limites impostos pelos anciãos, é possível dizer que os jovens também não estão aceitando os limites que os pais da ESP estão pretendendo impor. Se Lucius queria se arriscar, movendo-se para além dos limites, a rapaziada fez sua transgressão ocupando as escolas ${ }^{5}$. Ao ocupar a escola, estes alunos revoltam-se. E com esta revolta, dizem que não querem ser governados pelas forças que hoje tentam capturar sua potência, que querem ser governados de outro modo, que querem ser contraconduzidos. Se alguns pais se acham no direito de decidir pelos filhos o que eles irão estudar, estes jovens gritam que isto é o intolerável. E é contra o intolerável que é necessário insurgir-se. Pois, "se é contra o poder que se luta, então todos aqueles sobre quem o poder se exerce como abuso, todos aqueles que o reconhecem como intolerável, podem começar a luta onde se encontram e a partir de sua atividade (ou passividade) própria" (FOUCAULT, 1979, p.77).

A revolta não visa à vitória, acontecimento que se encerra em si mesmo, mas à produção de subjetividades insurgentes, que fazem de seus corpos pontos de resistência permanentes. O sujeito que se insurge não retorna a sua posição anterior, torna-se outro, pois revoltar-se é também cuidar

\footnotetext{
${ }^{5}$ Em 2016, estudantes secundaristas ocuparam mais de 1000 escolas no Brasil (EL PAÍS, 2016b, online). O estopim foi uma Emenda Constitucional que congelou os investimentos em Educação por 20 anos e uma reforma do Ensino Médio proposta pelo Governo sem discussões. Porém, nas falas de estudantes, temas relacionados às interdições do ESP estavam muito presentes, mostrando a resistência dos alunos. Ainda em 2016, ocorreu uma manifestação de alunos de uma escola privada paulista contra o ESP.
} 
de si (FOUCAULT, 2004). Não busca uma utopia, mas vislumbra a possibilidade de construir uma heterotopia (FOUCAULT, 2001) política, uma política outra, uma vida outra. Os alunos que ocuparam as escolas pretenderiam construir uma escola heterotópica, ou seja, pretenderiam fazer da escola um lugar que funcionasse de acordo com outras regras e que pudesse promover outras formas de existência.

As subjetividades insurgentes são subjetividades parresiastas, subjetividades que assumem a tarefa de um franco falar, mesmo quando este franco falar representa para elas um risco. Se as ocupações têm muitos rostos, talvez o rosto de Ana Júlia possa ser trazido agora como uma espécie de símbolo das subjetividades insurgentes e da ação corajosa do parresiasta. Ana Júlia, uma jovem estudante paranaense de 16 anos, não temia o risco que correu ao enfrentar sozinha os deputados da Assembleia Legislativa de seu Estado. Ela expôs na tribuna, com o seu franco falar, os motivos que estavam mobilizando os estudantes e indignou-se contra aqueles que os subestimaram como sujeitos capazes de uma revolta legítima. Ela enfrentou com sua fragilidade de menina os homens poderosos que se levantam contra ela (ROSSI, 2017).

É preciso notar que alguns acusaram os pais de Ana Júlia de doutrinar a filha, por terem uma vinculação histórica com o PT. Tendo em vista que o ESP se constitui justamente para exigir que os filhos sejam criados observando os valores familiares, por que a família de Ana Júlia não recebe apoio ao transmitir seus valores para a filha? Esses apoiadores da ESP parecem acreditar que os valores da esquerda não seriam saudáveis e moralmente aceitáveis para serem transmitidos aos filhos. Frente a isto, mais uma vez fica bastante evidente que a ESP não pretende, de modo algum, uma escola neutra e isenta de relações de poder. A ESP pretende preservar valores tradicionais e conservadores, deixando clara sua orientação ético-política.

\section{À GUISA DE CONCLUSÕES}

Voltando à analogia com o filme $A$ vila, os anciãos, assustados com a atitude corajosa de Lucius que desejava enfrentar os perigos para transgredir os limites impostos, não apenas negaram a autorização, como também simularam ataques à comunidade que teriam sido motivados por seu desejo de transgredir. Lucius aprendeu que sua transgressão não iria comprometer apenas a sua segurança, mas a de toda a vila, o que o fez desistir de partir. Os anciãos submeteram a potência criativa de Lucius inculcando-lhe a culpa e promovendo a rejeição da comunidade a sua ação, tendo em visto que ele não tinha medo. 
Parece-nos que o Governo Federal tentou fazer com estes jovens estudantes que desejavam transpassar os limites algo semelhante ao que o conselho de anciãos fez com Lucius. Frente à atitude corajosa das subjetividades insurgentes dos jovens, o MEC decidiu adiar a realização do ENEM daqueles que fariam a prova nas escolas ocupadas. Com isso, visava colocar a opinião pública contra as ocupações e, talvez, fazer com que os ocupantes se questionassem sobre os prejuízos que estariam causando a outros jovens.

Entendemos que a insurreição que aconteceu nas escolas foi promovida por uma multidão compostas de singularidades que se encontram para a defesa do comum (HARDT; NEGRI, 2005, 2016). Não há identidades, não se exigem filiações. A luta multitudinária é polimorfa e mutante. As ocupações são contra a Emenda Constitucional que congela as verbas para a Educação, são contra a reforma do ensino médio imposta por medida provisória pelo MEC e são contra o PL que quer instituir a escola sem partido. Mas também são para combater os microfascismos que se alojam em cada instituição e em cada indivíduo (FOUCAULT, 2017). As lutas são locais, as lutas são globais.

Talvez estes jovens lutem contra os três grandes inimigos que Foucault (2017, online) já antevia nos anos 1970: contra "aqueles que gostariam de preservar a ordem pura da política e do discurso político. [...] os funcionários da Verdade"; contra "os deploráveis técnicos do desejo [...] que gostariam de reduzir a organização múltipla do desejo à lei binária da estrutura e da falta" e, principalmente, contra

o inimigo maior, o adversário estratégico [...]: o fascismo. E não somente o fascismo histórico de Hitler e Mussolini, mas também o fascismo que está em todos nós, que ronda nossos espíritos e nossas condutas cotidianas, o fascismo que nos faz gostar do poder, desejar essa coisa mesma que nos domina e explora (FOUCAULT, 2017, online).

Deste modo, pensamos ser possível dizer que os anciãos da ESP pretendem domesticar a potência dos jovens que desejam transgredir os limites para que possam tomar o mundo em suas mãos. O ESP representa o aparelho de Estado, as duras linhas molares. Sua principal arma é a lei: o movimento vem propondo PL em todos os âmbitos, desde o municipal até o federal, passando pelos Estados. As ocupações nas escolas, por sua vez, são máquinas de guerra constituídas por linhas moleculares flexíveis em permanente bifurcação (DELEUZE; GUATTARI, 1996).

A ESP visa uma educação maior (GALLO, 2003), uma educação institucionalizada e enrijecida nos seus programas, nas suas metas. Os jovens nas ocupações pedem uma educação menor, que dê oportunidade à emergência de acontecimentos. Foucault (1995) nos dizia que as lutas atuais são antes de tudo, lutas pela subjetividade. Para além dos motivos concretos que tornaram possível as ocupações, pensamos que as motivações sejam muito mais complexas. Talvez estes 
jovens estejam a dizer que desejam uma educação mais ética e menos epistemológica. Que queiram uma educação para a insurgência e não para o assujeitamento. As ocupações nas escolas mostram o desejo de produzir linhas de fuga das máquinas de Estado, das intoleráveis sujeições, dos modos como suas condutas são conduzidas. As atividades nas ocupações, os aulões, as oficinas, mostram que não se negam a serem governados, mas querem ser governados de outros modos (FOUCAULT, 2000). Se no final do filme, Lucius morre, esperamos que nossos jovens continuem muito vivos com suas transgressões enfrentando os monstros que os/nos assombram. 


\section{REFERÊNCIAS}

BRASIL. MEC. SECAD. Apresentação. Disponível em <http://portal.mec.gov.br/secretaria-de-educacao-continuadaalfabetizacao-diversidade-e-inclusao/apresentacao >. Acesso em 27 set. 2017 a.

MPF. PFDC. Nota Técnica 02/2017/PFDC. Análise de vídeo e modelo de "notificação judicial" divulgados na Internet voltados a proibir a discussão sobre questões de gênero e orientação sexual nas escolas. Disponível em: 〈http://www.direitosdacrianca.gov.br/noticias-2017/NotaTcnican022017PFDC.pdf $>$. Acesso em 27 set. 2017b.

Casa Civil. Decreto 7.480, de 16 de maio de 2011. Aprova a Estrutura Regimental e o Quadro Demonstrativo dos Cargos em Comissão do Grupo-Direção e Assessoramento Superiores (DAS) e das Funções Gratificadas do Ministério da Educação. Brasília: Brasil, 2011. Disponível em: 〈http://www.planalto.gov.br/ ccivil 03/_ato20112014/2011/decreto/d7480.htm>. Acesso em 27 set. 2017.

; CNE. Resolução CNE/CEB 4, de 13 de julho de 2010. define Diretrizes Curriculares Nacionais Gerais para a Educação Básica. Disponível em: 〈http://portal.mec.gov.br/dmdocuments/rceb004_10.pdf〉. Acesso em 27 set. 2017.

; MEC. Decreto 5.159, de 28 de julho de 2004. Aprova a Estrutura Regimental e o Quadro Demonstrativo dos Cargos em Comissão e das Funções Gratificadas do Ministério da Educação. Brasília: Brasil, 2004. Disponível em: 〈http://portal.mec.gov.br/arquivos/pdf/d5159.pdf>. Acesso em 27 set. 2017.

; MEC. Lei 9.394, de 20 de dezembro de 1996. Estabelece as diretrizes e bases da educação nacional. Brasília: Brasil, 1996. Disponível em: 〈https://www2.senado.leg.br/bdsf/bitstream/handle/id/70320/65.pdf〉. Acesso em 27 set. 2017.

CIDH. Convenção Americana de Direitos Humanos. Costa Rica: Conferência Especializada Interamericana sobre Direitos Humanos, 1969. Disponível em: 〈https://www.cidh.oas.org/basicos/portugues/c.convencao_americana.htm〉. Acesso em 27 set. 2017.

DCM. Escola sem Partido intimida e persegue professores. 6 de ago. de 2017. Disponível em: $<$ http://www.diariodocentrodomundo.com.br/escola-sem-partido-intimida-e-persegue-professores/>. Acesso em 27 set. 2017.

DELEUZE, G.; GUATTARI, F. Mil platôs: capitalismo e esquizofrenia, vol. 3. Rio de Janeiro: Ed. 34, 1996.

DIP. A. Escola Sem Partido caça bruxas nas salas de aula. Sul 21, 30 ago. 2016. Disponível em: <https://www. sul21.com.br/jornal/escola-sem-partido-caca-bruxas-nas-salas-de-aula/>. Acesso em 27 set. 2017.

EL PAÍS. A onda 'QueerMuseu' tentou cercear outras obras. Mas encontrou resistência. 21 set. 2017. Disponível em: 〈https://brasil.elpais.com/brasil/2017/09/21/cultura/1506018494_703601.html〉. Acesso em 26 set. 2017.

O professor da minha filha comparou Che Guevara a São Francisco de Assis. 25 jun. 2016a. Disponível em < https://brasil.elpais.com/brasil/2016/06/23/politica/1466654550_367696.html〉. Acesso em 27 set. 2017.

PEC 241: Com quase 1.000 escolas ocupadas no país, ato de estudantes chega a SP. 25 out. $2016 \mathrm{~b}$. Disponível em https://brasil.elpais.com/brasil/2016/10/24/politica/1477327658_698523.html. Acesso em 28 set. 2017.

. Movimento Escola sem Partido. Disponível em <http://escolasempartido.org/>. Acesso em 27 set. 2017 a.

ESP. Programa Escola sem Partido. Disponível em <https://www.programaescolasempartido.org/>. Acesso em 27 set. 2017b.

ESTADÃO. Vereador Fernando Holiday faz blitz em escolas para verificar 'doutrinação' 04 abr. 2017. Disponível em 〈http://educacao.estadao.com.br/noticias/geral,vereador-fernando-holiday-faz-blitz-em-escolas-para-verificar-doutrinacao.70001726796〉. Acesso em 27 set. 2017.

FOLHA DE SÃo PAUlO. Estudantes protestam contra Escola Sem Partido em colégio de SP. 12 ago. 2016. Disponível em http://www1.folha.uol.com.br/educacao/2016/08/1802103-estudantes-protestam-contra-escola-sempartido-em-colegio-de-sp.shtml> Acesso em 27.set. 2017.

FOUCAULT, M. É inútil revoltar-se? In: FOUCAULT, Michel. Ditos \& escritos V: Ética, sexualidade, política. Rio de Janeiro: Forense universitária, 2004. p. 77-81.

Introdução à vida não fascista. Disponível em <http://www.coloquiofoucault2008.mpbnet.com.br/por_uma vida nao fascista.html $>$. Acesso em 27 set. 2017.

Le courage de la vérité. Paris: Gallimard/Seuil, 2009. 
FOUCAUlT, M. O que é a crítica? (Crítica e Aufklärung). Cadernos da F.F.C., Marília, UNESP, v. 9, n. 1, p. 169$189,2000$.

Outros espaços. In: FOUCAULT, Michel. Ditos \& escritos III: Estética. Rio de Janeiro: Forense universitária, 2001. p. 411-422.

. Microfísica do poder. Rio de Janeiro: Graal, 1979.

. O sujeito e o poder. In: RABINOW, Paul; DREYFUS, Hubert. Michel Foucault: uma trajetória filosófica para além do estruturalismo e da hermenêutica. Rio de Janeiro: Forense Universitária, 1995. p. 231-249.

GALLO, S. Deleuze \& a Educação. Belo Horizonte: Autêntica Editora, 2003.

HARDT, M.; NEGRI, A. Bem-estar comum. Rio de Janeiro: Record, 2016.

. NEGRI, A. Multidão. Rio de Janeiro: Record, 2005.

LOPES, A. C.; MACEDO, E. Teorias do currículo. São Paulo: Cortez, 2011.

MASSCHELEIN, J.; SIMON, M. Em defesa da escola. Belo Horizonte: Autêntica, 2013.

ROSSI, M. Ana Júlia e o emotivo discurso que explica os protestos nas escolas ocupadas. El País, 31 out. 2016. Disponível em <https://brasil.elpais.com/brasil/2016/10/27/politica/1477567372_486778.html>. Acesso em 27 set. 2017.

VARELA, J.; ALVAREZ-URIA, F. A maquinaria escolar. Teoria \& Educação, São Paulo, n. 6, p. 68-96, 1992. 


\section{RESUMO}

O Movimento Escola sem Partido (ESP) vem promovendo, de forma crescente, ações de controle e coerção ao trabalho docente. No intuito de afastar a possibilidade de uma doutrinação por meio das práticas em sala de aula, o ESP incentiva a denúncia por parte de pais e alunos, visando instaurar uma vigilância pervasiva e ubiqua sobre os professores. O objetivo deste artigo é problematizar os perigos que a disseminação das ideias do ESP pode (im)por à Educação, seja em relação à ação docente, seja em relação à formação das próximas gerações, a partir de um quadro teórico de orientação pós-estruturalista.

Palavras - chave: Escola sem Partido - Docência - Alunos.

\section{THE DANGERS OF NO PARTY SCHOOL}

\section{ABSTRACT}

The No Party School Movement (ESP) has been increasingly promoting control and coercion actions on teaching work. In order to avoid the possibility of indoctrination through classroom practices, the ESP encourages the denunciation by parents and students, aiming to establish a pervasive and ubiquitous vigilance over teachers. The purpose of this article is to problematize the dangers that the dissemination of ESP ideas can put on Education, in relation to the teaching action and in relation to the formation of the next generations, from a theoretical framework of poststructuralist orientation.

Keywords: No Party School - Teaching - Students.

\section{LOS PELIGROS DE LA ESCUELA SIN PARTIDO}

\section{RESUMEN}

El Movimiento Escuela sin Partido (ESP) promueve, desde hace algún tiempo y de forma creciente, acciones de control y coerción al trabajo docente. Con el objetivo de anular la posibilidad de un adoctrinamiento por medio de las prácticas en el aula, el ESP incentiva la denuncia por parte de padres y alumnos, buscando instaurar una vigilancia opresora y ubicua sobre los profesores. Con este artículo se busca problematizar los peligros que supone para la Educación la diseminación de las ideas del ESP, ya sea con respecto a la acción docente o con relación a la formación de las próximas generaciones, a partir de un marco teórico de orientación posestructuralista.

Palabras clave - Escuela sin Partido - Docencia - Alumnos. 